\title{
Use of Viscosity to Probe the Interaction of Anionic Surfactants with a Coagulant Protein from Moringa oleifera Seeds
}

\author{
Raymond Maikokera and Habauka M. Kwaambwa \\ Department of Chemistry, University of Botswana, Private Bag UB 00704 Gaborone, Botswana \\ Correspondence should be addressed to Habauka M. Kwaambwa, kwaambwa@mopipi.ub.bw \\ Received 5 March 2009; Accepted 10 April 2009 \\ Recommended by Benjaram M. Reddy
}

\begin{abstract}
The intrinsic viscosity of the coagulant protein was evaluated from the flow times of the protein solutions through a capillary viscometer, and the results suggested the coagulant protein to be globular. The interactions of the coagulant protein with anionic surfactant sodium dodecyl sulphate (SDS) and sodium dodecyl benzene sulfonate (SDBS) were also investigated by capillary viscometry. We conclude that there is strong protein-surfactant interaction at very low surfactant concentrations, and the behavior of the anionic surfactants in solutions containing coagulant protein is very similar. The viscometry results of protein-SDS system are compared with surface tension, fluorescence, and circular dichroism reported earlier. Combining the results of the four studies, the four approaches seem to confirm the same picture of the coagulant protein-SDS interaction. All the physical quantities when studied as function of surfactant concentration for $0.05 \%(\mathrm{w} / \mathrm{v})$ protein solution either exhibited a maximum or minimum at a critical SDS concentration.
\end{abstract}

Copyright (C) 2009 R. Maikokera and H. M. Kwaambwa. This is an open access article distributed under the Creative Commons Attribution License, which permits unrestricted use, distribution, and reproduction in any medium, provided the original work is properly cited.

\section{Introduction}

Moringa oleifera is a multipurpose tropical tree with most of its parts being useful for medicinal and commercial applications in addition to its nutritional value [1-8]. The seeds from this plant contain active coagulating agents characterized as dimeric cationic proteins having a molecular weight of $13 \mathrm{kDa}$ and an isoelectric $\mathrm{pH}$ between 10 and 11 [2]. It is suggested that in the near future, coagulating protein extracted from Moringa oleifera seeds could be a potential challenger of synthetic coagulants (e.g., iron chloride and aluminium sulphate) for water purification [3] and for primary treatment of industrial and domestic wastewaters [9]. As a result, it has been recommended by the Food and Agricultural Organization (FAO) as a proper and advisable way for treating water [8]. Recently, protein extract from Moringa oleifera seeds has been found to be an anionic surfactant-removal agent in aqueous solutions [4].Thus, it is important to keep on researching on protein extracts from Moringa's properties.

The interaction between surfactants and proteins is an active field of research in colloid science because very often in practice the proteins and surfactants are present in the same systems such as industrial, biological, pharmaceutical, and cosmetic systems. In addition, physicochemical characterisation of seed proteins is important in order to understand the nature of the protein and its interaction with other components.

It is known in general that anionic surfactants interact strongly with proteins and form protein-surfactant complexes, which would induce the unfolding of proteins [10]. The sensitivity of viscosity to molecular structure makes it useful for monitoring processes that result in changes in overall protein conformation [11, 12]. Apart from viscosity measurements, other classical techniques such as surface tension and fluorescence spectroscopy have been employed to examine the occurrence of critical phenomena in solution properties of protein-surfactant mixtures $[13,14]$. As has been established using surface tensiometry and intrinsic fluorescence spectroscopy, the anionic surfactant sodium dodecyl sulphate (SDS) interacts strongly with the coagulant protein from Moringa oleifera seeds [15]. Similar interactions were observed between the coagulant protein and the anionic surfactant sodium bis(2-ethyl-1-hexyl)sulfosuccinate (AOT) when monitored by surface tension probe [16]. 
In this work, the effects of the presence of anionic surfactants SDS and SDBS on the viscosity properties of the coagulant protein from Moringa oleifera are reported. The results of solution properties of the protein in the presence of SDS are verified by surface tension, circular dichroism, and fluorescence measurements reported earlier [15-18].

\section{Materials and Methods}

2.1. Extraction and Purification. The extraction and purification of protein powder was done using the method of Ndabigengesere and Narasiah [3], and the experimental details are described in our previous work [15-18].

\subsection{Viscosity and Protein-Surfactant Interactions Measure-} ments. The viscosity measurements were carried out using an Ubbelohde suspended-level capillary viscometer. The viscometer was suspended vertically in a thermostat water bath at $25 \pm 0.1^{\circ} \mathrm{C}$. The solutions were allowed to equilibrate for 10 minutes before beginning timed runs. The flow time of a constant volume of solution through the capillary was measured with a digital stopwatch.

The intrinsic viscosity $[\eta]$ of the coagulant protein was measured for protein concentration, $c$, in the range $0.02-$ $0.15 \mathrm{~g} / \mathrm{mL}$ in $0.1 \mathrm{M} \mathrm{NaCl}$. Solution environment such as presence of surfactants can affect protein conformation. To study interactions SDS and SDBS with the coagulant protein, capillary viscosities of the surfactant/protein solutions were measured using a capillary viscometer. The protein concentration $(\% \mathrm{w} / \mathrm{v})$ was kept constant at $0.05 \%$ whereas the surfactant concentration was varied up to concentrations higher than the critical micelle concentration $(C M C)$. The protein solution was used as the reference standard for surfactant dissolved in $0.05 \%$ protein. The SDS (99\% purity) was supplied by Sigma-Aldrich whereas SDBS was supplied by Fluka, and both surfactants were used without further purification. The measurements of surface tension, fluorescence, and circular dichroism spectral correlation coefficients of SDS solutions in the presence of protein were done in similar manner, and the details are described elsewhere [15$18]$.

\section{Results and Discussion}

3.1. Intrinsic Viscosity. For background ionic strength capable of swamping contributions to the ionic strength from the protein, the Huggins and Kraemer equations, respectively, are

$$
\begin{gathered}
\frac{\eta_{s p}}{c}=[\eta]_{H}+k_{H}[\eta]_{H}^{2} c, \\
\ln \frac{\eta_{\mathrm{r}}}{\mathrm{c}}=[\eta]_{K}+k_{K}[\eta]_{K}^{2} c,
\end{gathered}
$$

where $\eta_{r}$ is the relative viscosity, $\eta_{s p}\left(=\eta_{r}-1\right)$ is the specific viscosity, $c$ is the protein concentration, and $k_{H}$ and $k_{K}$ are the Huggins and Kraemer's constants, respectively, [19-21]. $\eta_{s p}$ is dependent on concentration and interaction forces. Figure 1 shows the plots obtained by fitting the experimental

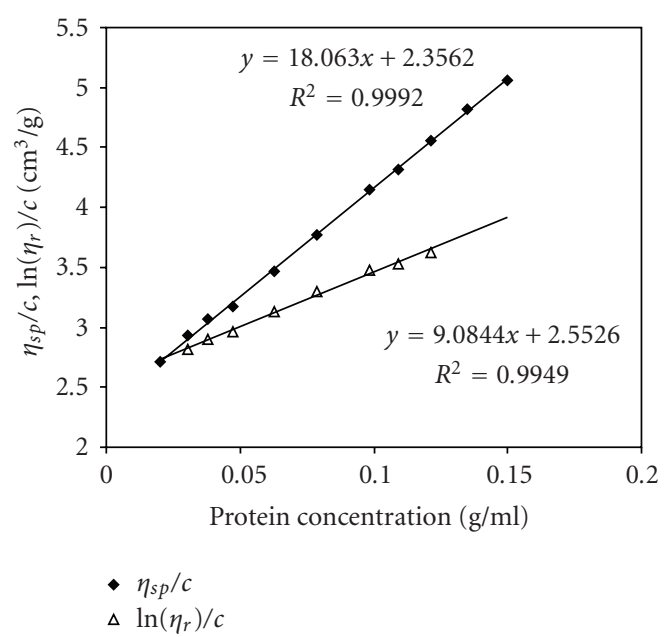

Figure 1: Evaluation of intrinsic viscosity for solutions in $0.1 \mathrm{M}$ $\mathrm{NaCl}$ of the coagulant protein at $25^{\circ} \mathrm{C}$. The Huggins (filled diamonds) and Kraemer (open triangles) plot give $[\eta]_{H}=$ $2.4 \mathrm{~mL} / \mathrm{g}$ and $[\eta]_{K}=2.6 \mathrm{~mL} / \mathrm{g}$, respectively.

data to (1). The plots are linear with statistical correlation coefficient, $R^{2}$, of 0.999 and 0.995 for Huggins plot and Kraemer plot, respectively. Thus, the $[\eta]$ was estimated from the intercepts, giving $[\eta]_{H}=2.4 \mathrm{~mL} / \mathrm{g}$ and $[\eta]_{K}=$ $2.6 \mathrm{~mL} / \mathrm{g}$. Thus, $[\eta]$ of the coagulant protein was estimated as the average of the two values is $2.5 \mathrm{~mL} / \mathrm{g}$. Very high protein concentrations (up to $0.15 \mathrm{~g} / \mathrm{mL}$ ) were used for intrinsic viscosity determination. If the polymer concentration is very high while the intrinsic viscosity is very low, the molecule must be globular with a compact, nearly spherical shape [12]. The $[\eta]$ has been defined as the shape factor, and a value between 2.5 and $4 \mathrm{~mL} / \mathrm{g}$ indicates globular particles [22].

3.2. Protein-Surfactant Interaction. Viscometry is effective in probing conformational changes due to interaction of protein with ionic surfactants [23]. The measurement of solution viscosity was performed to monitor the interaction of the coagulant protein with anionic surfactants SDS and SDBS in water. Results in Figure 2 show that addition of the anionic surfactants to the protein solutions gives a strong initial increase in viscosity and then a decrease, through a maximum at $0.768 \mathrm{mM}$ surfactant concentration. The maximum suggests a change in the conformation of the protein structure or aggregation [24]. Upon further increase in the surfactant concentration above $2 \mathrm{mM}$, the viscosity increases gradually (Figure 2), suggesting protein restructuring and a significant expansion of the protein molecule coil in solution [24]. The behavior of the two anionic surfactants in solutions containing coagulant protein is very similar.

It is not possible from viscosity measurements alone to establish the origin of the viscosity changes that occur when surfactants are added to the coagulant protein solutions. A variety of physicochemical phenomena may contribute to the overall viscosity changes, including surfactant binding, protein aggregation, protein conformational changes, and 


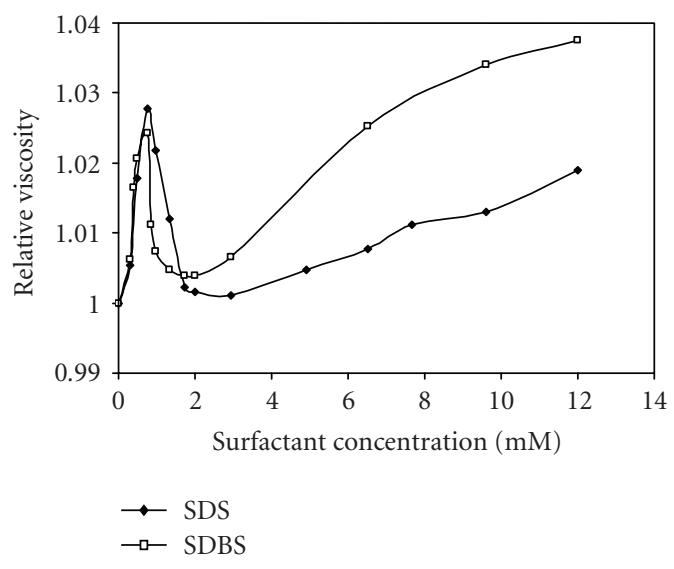

FIGURE 2: Influence of anionic surfactants on the relative viscosity of solutions containing $0.05 \%$ of the coagulant protein in water at $25^{\circ} \mathrm{C}$.

surfactant micellization. The large increase in viscosity at low surfactant concentration may indicate the formation of aggregates. The coagulant protein is highly cationic in water (i.e., in the absence of surfactants) because the protein is below its isoelectric point [2]. Consequently, there is an electrostatic repulsion between the protein molecules that is large enough to prevent them from associating [25]. Thus, at a very low surfactant concentration, there should be strong electrostatic interactions between the negatively charged surfactants and the positively charged groups in the coagulant protein. This reduces the net positive charge on the protein, and eventually, electrical net charge would no longer be large enough to prevent the protein-surfactant complexes formed from aggregating [26]. This is the surfactant concentration where the electrical charge on the protein molecules is close to zero, that is, charge neutralization occurs [26]. Further binding of anionic surfactant to the protein molecules caused them to gain a net negative charge sufficiently large such that electrostatic repulsions between the protein-surfactant molecules oppose aggregation, and so the aggregates would dissolve [25], which could explain why the solution viscosity decreases again (Figure 2).

\subsection{Combined Analysis of the Coagulant Protein-SDS Interac-} tion. In this section, the viscosity data was directly compared to earlier reported surface tension [15, 16], fluorescence [17], and $\mathrm{CD}$ [18] data of the coagulant protein-SDS interaction studies (Figure 3). Similar SDS concentration ranges were used, and it was convenient to divide the profiles into four different regions depending on the SDS concentration.

The main point is that in region I, $(<2 \mathrm{mM}$ SDS $)$, the bulk solution and interfacial properties exhibit critical behavior (marked by the arrows in Figure 3 ). It can be seen that the minimum in the spectral correlation coefficients and maxima in the relative viscosity, fluorescence intensity, and surface tension occurs at approximately the same concentration of SDS of about $1 \mathrm{mM}$. The authors suggest that this marks the stoichiometric balance point, where charge neutralization between the negatively charged SDS

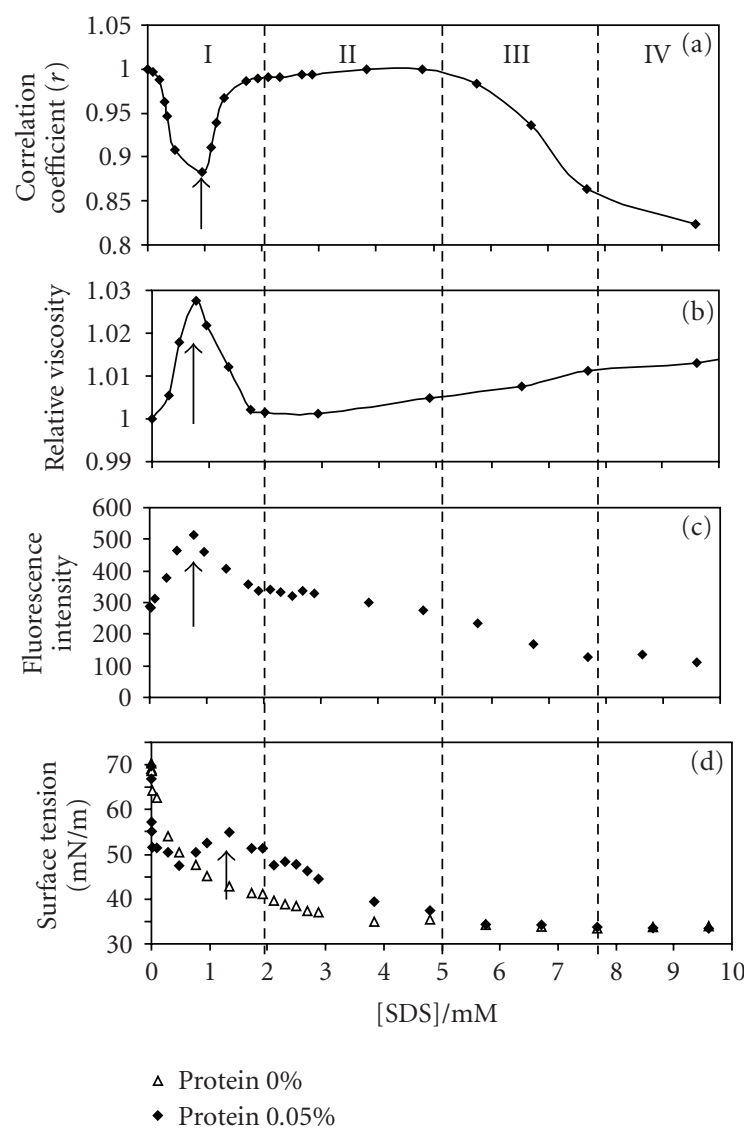

FIgURE 3: Variation with SDS concentration of (a) spectral correlation coefficient, (b) relative viscosity, (c) protein fluorescence intensity and (d) surface tension in the presence of protein. The protein concentration was $0.05 \% \mathrm{w} / \mathrm{v}$.

and the positively charged fragments in the coagulant protein occur [27-29]. Below $1 \mathrm{mM}$ SDS, it is suggested that the coagulant protein-SDS complexes form aggregates.

Although charge neutralization and aggregation of protein/surfactant mixtures has been reported before $[25,26$, $30,31]$, the conclusion that the SDS bound to the coagulant protein promotes protein aggregation $([\mathrm{SDS}]<1 \mathrm{mM})$ and opposes protein aggregation $(1 \mathrm{mM}<[S \mathrm{SD}]<2 \mathrm{mM})$ is presently not well understood. But it does provide the framework for testable models. These issues are being addressed in our on-going research work.

\section{Conclusions}

The determined intrinsic viscosity of the coagulant protein is $2.5 \mathrm{~mL} / \mathrm{g}$. The intrinsic viscosity value suggests globular nature. The interaction between the coagulant protein and anionic surfactants, SDS and SDBS, in aqueous medium was investigated by viscometry and compared with tensiometry, fluorescence, and CD results previously reported. The occurrence of critical phenomena in solution properties of mixed coagulant protein-anionic surfactants system has been observed. Put together, these four approaches seem 
to confirm the same picture of the coagulant protein-SDS interaction.

\section{Acknowledgments}

The authors wish to acknowledge German Academic Exchange Service (DAAD) and the University of Botswana Office of Research and Development (ORD) for the financial support in form of a fellowship for RM and research grant for HMK, respectively. Dr. C. Nakabale (nakabale@botsnet.bw, Mahalpye, Botswana) is also acknowledged for the supply of Moringa oleiferaseeds.

\section{References}

[1] J. P. Sutherland, G. K. Folkard, M. A. Mtawali, and W. D. Grant, "Moringa oleifera as a natural coagulant," in Proceedings of the 20th WEDC Conference Affordable Water Supply and Sanitation, pp. 297-299, Colombo, Sri Lanka, August 1994.

[2] A. Ndabigengesere, K. S. Narasiah, and B. G. Talbot, "Active agents and mechanism of coagulation of turbid waters using Moringa oleifera," Water Research, vol. 29, no. 2, pp. 703-710, 1995.

[3] A. Ndabigengesere and K. S. Narasiah, "Quality of water treated by coagulation using Moringa oleifera seeds," Water Research, vol. 32, no. 3, pp. 781-791, 1998.

[4] J. Beltrán-Heredia and J. Sánchez-Martín, "Removal of sodium lauryl sulphate by coagulation/flocculation with Moringa oleifera seed extract," Journal of Hazardous Materials, vol. 164, no. 2-3, pp. 713-719, 2009.

[5] T. L. Hart, "Natural coagulants: an investigation of Moringa oleifera and Tamarind seeds," MSc Report, University of Texas, Austin, Tex, USA, 2000.

[6] G. K. Folkard and J. P. Sutherland, "The use of Moringa oleifera seed as a natural coagulant for water and wastewater treatment," in Proceedings of Simposio Internacional Sobre Tecnologias Deapolo a Gestao De Recursos Hidricos, 2001, may 2007, http://www.isesd.cv.ic.ac.uk.

[7] K. A. Ghebremichael, Moringa oleifera and Pumice as alternative natural materials for drinking water treatment, Ph.D. thesis, Kungl Tekniska Högskolan, Stockholm, Sweden, 2004.

[8] S. A. A. Jahn, H. A. Musnad, and H. Burgstaller, "The tree that purifies water: cultivating multipurpose Moringaceae in the Sudan," Unasylva, vol. 38, no. 152, pp. 23-28, 1986.

[9] Y. Kalogo, F. Rosillon, F. Hammes, and W. Verstraete, "Effect of a water extract of Moringa oleifera seeds on the hydrolytic microbial species diversity of a UASB reactor treating domestic wastewater," Letters in Applied Microbiology, vol. 31, no. 3, pp. 259-264, 2000.

[10] E. D. Goddard and K. P. Ananthapadmanabhan, Interactions of Surfactants with Polymers and Proteins, CRC Press, Boca Raton, Fla, USA, 1993.

[11] J. S. Barton, "Protein denaturation and tertiary structure," Journal of Chemical Education, vol. 63, no. 4, pp. 367-368, 1986.

[12] J. L. Richards, "Viscosity and the shapes of macromolecules: a physical chemistry experiment using molecular-level models in the interpretation of macroscopic data obtained from simple measurements," Journal of Chemical Education, vol. 70, no. 8 , pp. $685-689,1993$.
[13] B. Lindman, "Surfactant-polymer systems," in Handbook of Applied Surface and Colloid Chemistry, Vol. 1, R. Holmberg, Ed., pp. 445-463, John Wiley \& Sons, New York, NY, USA, 2001.

[14] R. Nagarajan, "Polymer-surfactant interactions," in New Horizons: Detergents for the New Millennium Conference Invited Paper, American Oil Chemists Society and Consumer Specialty Products Association, Fort Myers, Fla, USA, 2001.

[15] R. Maikokera and H. M. Kwaambwa, "Interfacial properties and fluorescence of a coagulating protein extracted from Moringa oleifera seeds and its interaction with sodium dodecyl sulphate," Colloids and Surfaces B, vol. 55, no. 2, pp. 173-178, 2007.

[16] H. M. Kwaambwa and R. Maikokera, "Air-water interface interaction of anionic, cationic, and non-ionic surfactants with a coagulant protein extracted from Moringa oleifera seeds studied using surface tension probe," Water SA, vol. 33, no. 4, pp. 583-588, 2007.

[17] H. M. Kwaambwa and R. Maikokera, "A fluorescence spectroscopic study of a coagulating protein extracted from Moringa oleifera seeds," Colloids and Surfaces B, vol. 60, no. 2, pp. 213220, 2007.

[18] H. M. Kwaambwa and R. Maikokera, "Infrared and circular dichroism spectroscopic characterisation of secondary structure components of a water treatment coagulant protein extracted from Moringa oleifera seeds," Colloids and Surfaces $B$, vol. 64, no. 1, pp. 118-125, 2008.

[19] P. A. Lovell, "Dilute solution viscometry," in Comprehensive Polymer Science: Polymer Characterization, Vol. 1, C. Price and C. Booth, Eds., pp. 175-197, Pergamon Press, Oxford, UK, 1989.

[20] G. L. Flickinger, I. S. Dairanieh, and C. F. Zukoski, "The rheology of aqueous polyurethane dispersions," Journal of Non-Newtonian Fluid Mechanics, vol. 87, no. 2-3, pp. 283-305, 1999.

[21] L. C. Rosenthal, "A polymer viscosity experiment with no right answer," Journal of Chemical Education, vol. 67, no. 1, pp. 7880, 1990.

[22] S. R. Patil, T. Mukaiyama, and A. K. Rakshit, "Interfacial, thermodynamic, and performance properties of $\alpha$-sulfonato myristic acid methyl ester-hexaoxyethylene monododecyl ether mixed surfactants," Journal of Dispersion Science and Technology, vol. 24, no. 5, pp. 659-671, 2003.

[23] R.-C. Lu, A.-N. Cao, L.-H. Lai, B.-Y. Zhu, G.-X. Zhao, and J.-X. Xiao, "Interaction between bovine serum albumin and equimolarly mixed cationic-anionic surfactants decyltriethylammonium bromide-sodium decyl sulfonate," Colloids and Surfaces B, vol. 41, no. 2-3, pp. 139-143, 2005.

[24] P. Deo, S. Jockusch, M. F. Ottaviani, A. Moscatelli, N. J. Turro, and P. Somasundaran, "Interactions of hydrophobically modified polyelectrolytes with surfactants of the same charge," Langmuir, vol. 19, no. 26, pp. 10747-10752, 2003.

[25] D. Kelley and D. J. McClements, "Interactions of bovine serum albumin with ionic surfactants in aqueous solutions," Food Hydrocolloids, vol. 17, no. 1, pp. 73-85, 2003.

[26] S. Magdassi, Y. Vinetsky, and P. Relkin, "Formation and structural heat-stability of $\beta$-lactoglobulin/surfactant complexes," Colloids and Surfaces B, vol. 6, no. 6, pp. 353-362, 1996.

[27] N. Plucktaveesak, A. J. Konop, and R. H. Colby, "Viscosity of polyelectrolyte solutions with oppositely charged surfactant," The Journal of Physical Chemistry B, vol. 107, no. 32, pp. 81668171, 2003. 
[28] R. J. Green, T. J. Su, H. Joy, and J. R. Lu, "Interaction of lysozyme and sodium dodecyl sulfate at the air-liquid interface," Langmuir, vol. 16, no. 13, pp. 5797-5805, 2000.

[29] M. D. Lad, V. M. Ledger, B. Briggs, R. J. Green, and R. A. Frazier, "Analysis of the SDS-lysozyme binding isotherm," Langmuir, vol. 19, no. 12, pp. 5098-5103, 2003.

[30] A. D. Nielsen, L. Arleth, and P. Westh, "Analysis of proteinsurfactant interactions-a titration calorimetric and fluorescence spectroscopic investigation of interactions between Humicola insolens cutinase and an anionic surfactant," Biochimica et Biophysica Acta, vol. 1752, no. 2, pp. 124-132, 2005.

[31] Y. Vinetsky and S. Magdassi, "Properties of complexes and particles of gelatin with ionic surfactants," Biochimica et Biophysica Acta, vol. 276, no. 5, pp. 395-401, 1998. 


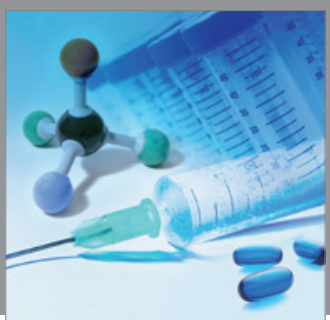

International Journal of

Medicinal Chemistry

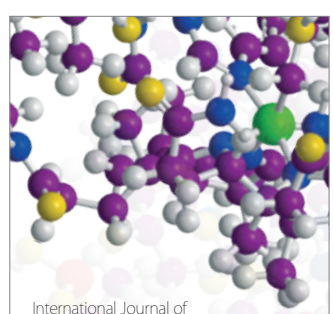

Carbohydrate Chemistry

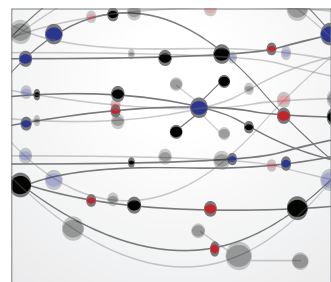

The Scientific World Journal
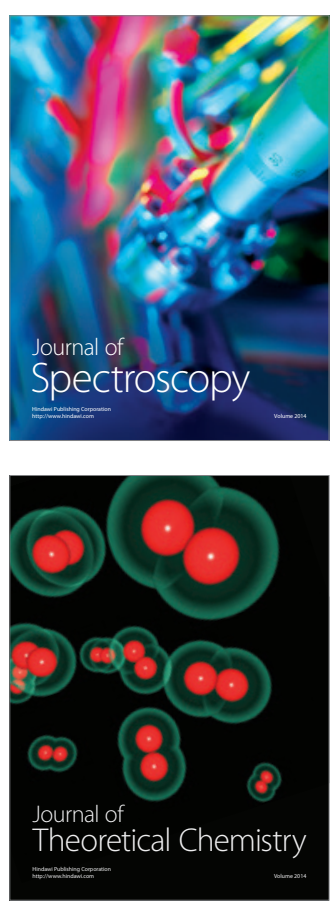
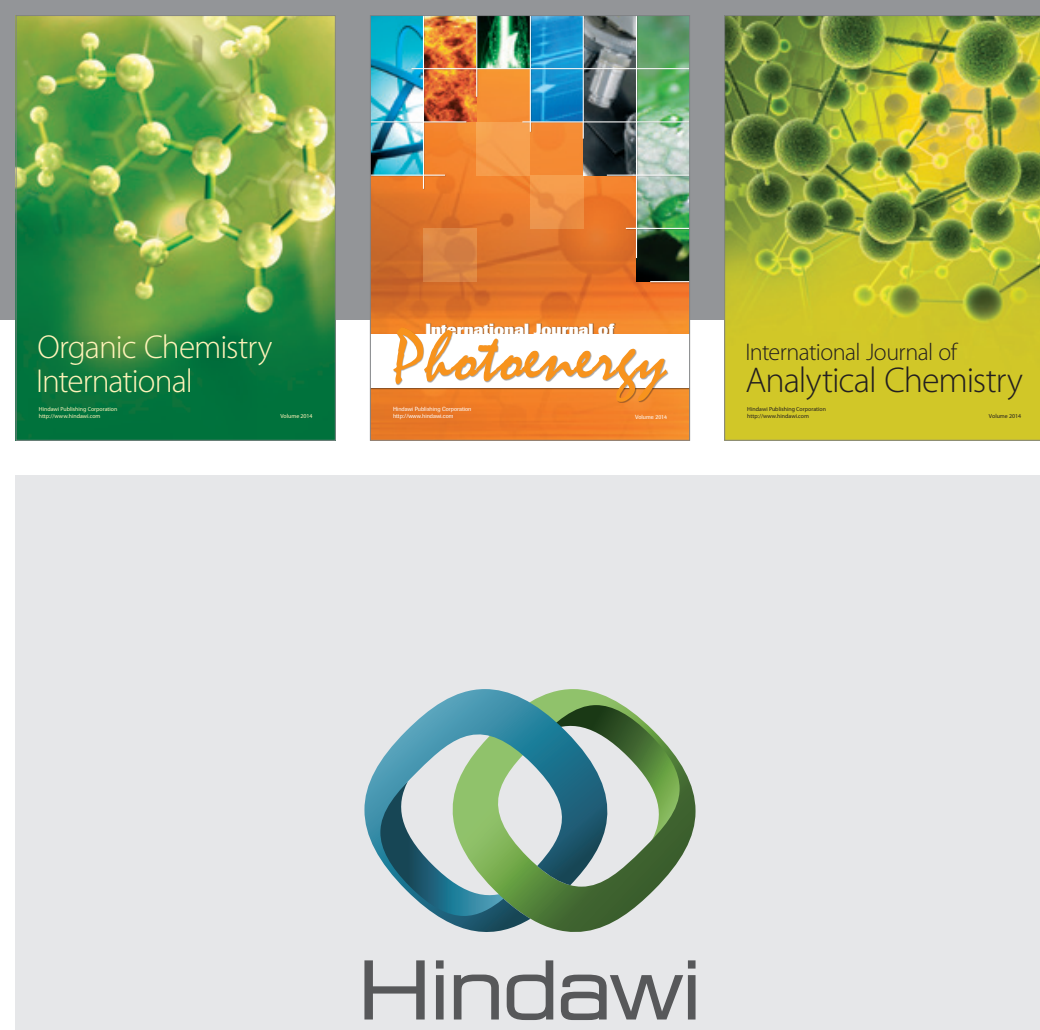

Submit your manuscripts at

http://www.hindawi.com
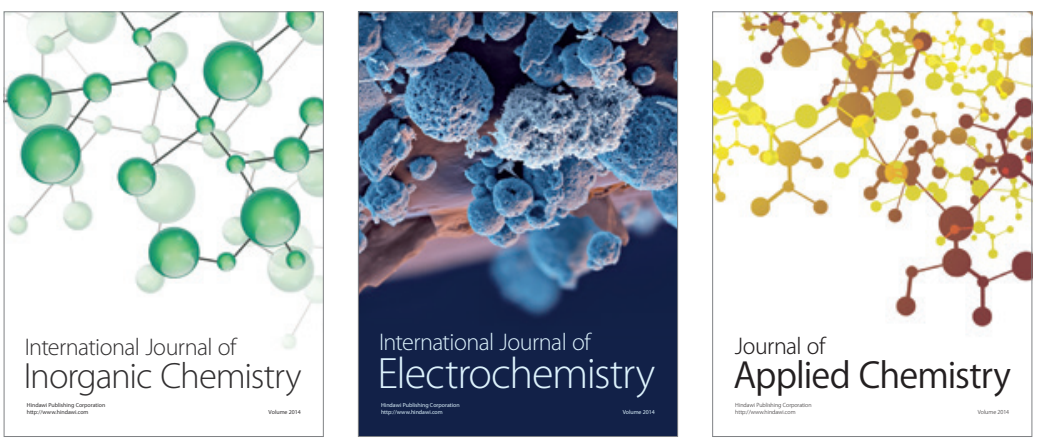

Journal of

Applied Chemistry
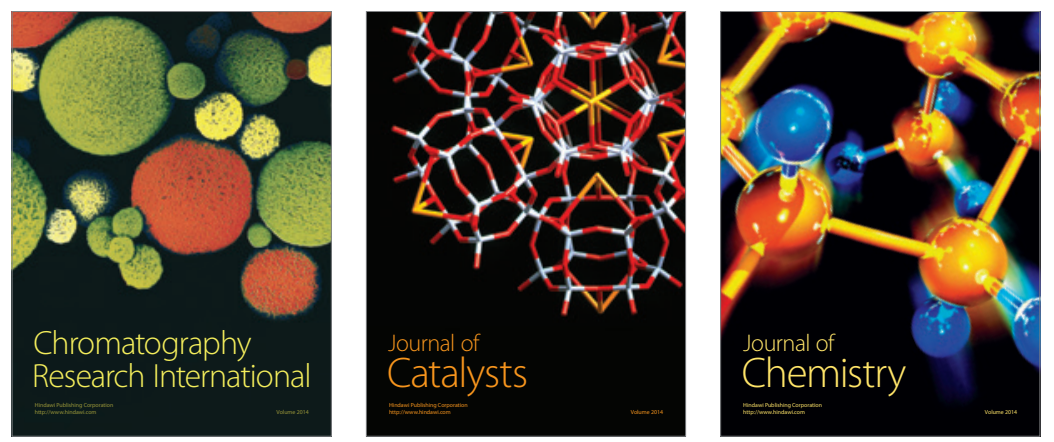
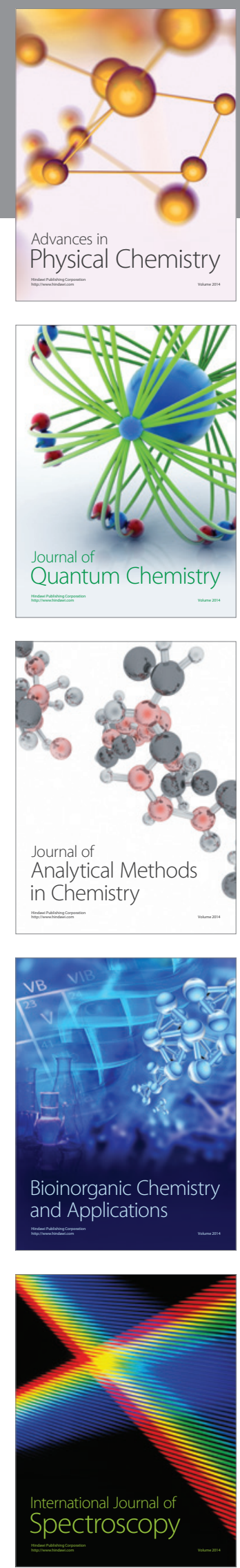